\title{
O Genograma como Instrumento de Pesquisa do Impacto de Eventos Estressores na Transição Família-Escola
}

\author{
The Genogram as a Research Instrument of the Impact Of Stressful Events \\ in the Family-School Transition
}

\author{
Luciana Castoldi*, Rita de Cássia Sobreira Lopes \& Laíssa Eschiletti Prati \\ Universidade Federal do Rio Grande do Sul, Porto Alegre, Brasil
}

\begin{abstract}
Resumo
O início da vida escolar é um momento especial dentro do ciclo vital que pode ser dificultado por eventos estressores tais como perdas e separações familiares, assim como por padrões de relacionamento conflituosos entre a família atual e a de origem. Neste ar tigo, pretende-se demonstrar o uso do genograma como instrumento de pesquisa em psicologia do desenvolvimento, com os seguintes objetivos: caracterizar as configurações familiares, identificar eventos estressores no ciclo vital das famílias, em especial, as perdas e separações, e analisar os padrões de relacionamento entre a família atual e a de origem. Realizou-se estudo de caso coletivo com seis famílias de crianças de cinco a seis anos, três delas consideradas como tendo adaptação fácil e três com adaptação difícil à escola de educação infantil. As mães foram entrevistadas e solicitadas a construir seu genograma familiar. Foram encontradas características específicas e distintas quanto às configurações familiares, aos eventos estressores na família atual e aos padrões de relacionamento nos dois grupos analisados. As implicações do uso do genograma como instrumento de pesquisa do impacto de eventos estressores na transição família-escola são discutidas.

Palavras-chave. Genograma; perdas; separação; padrões de relacionamento familiar.
\end{abstract}

\begin{abstract}
The beginning of school life is a special moment in the life cycle that may be influenced by stressful events such as family loss and separation, as well as by conflicting relationship patterns between the present family and the family of origin. This article aims to demonstrate the use of the genogram as a research instrument in developmental psychology with the following objectives: characterize the family configurations, identify stressful events in the families' life cycle, especially, loss and separation experiences, and to analyze the relationship patterns between the nuclear family and the family of origin. A collective case study was carried out with six families and their children age five to six, three of whom were considered as having an easy adaptation to school and the other three as having a difficult adaptation. The mothers were interviewed and asked to construct their family genograms. Specific and distinct features were found regarding family configurations, stressful life events and relationship patterns in each group. The implications of the use of the genogram as a research instrument of the impact of stressful events in the family-school transition are discussed.

Keywords: Genogram; loss; separation; family relationship patterns.
\end{abstract}

A entrada da criança na escola é uma etapa fundamental no desenvolvimento infantil e familiar. Embora se saiba que a trajetória família-escola é inevitável, nem sempre este é um percurso fácil. As crianças ingressam cada vez mais jovens nas instituições formais de ensino e nem sempre elas, a escola ou a família estão preparadas para esta nova experiência de separação.

Na perspectiva do ciclo vital da teoria sistêmica (Andolfi \& Angelo, 1988; Bowen, 1979/1991; Carter \& McGoldrick, 1989/1995; Falicov, 1991; Minuchin \& Fishman, 1990), entende-se que os momentos mais sensíveis para o desenvolvimento familiar estão na transição de uma etapa do ciclo vital para outra. Na etapa da família com filhos pequenos, aceitar que o filho está preparado ou necessita

\footnotetext{
*Endereço para correspondência: Rua José Honorato dos Santos, 100/401 - Porto Alegre, RS, 90050 040. Fone: (54) 3212 5541. E-mail: lucianacastoldi@uol.com.br
}

freqüentar o ambiente escolar, seria um destes momentos vulneráveis, denominados por Carter e McGoldrick de estressores desenvolvimentais ou "horizontais".

Para as autoras, a família pode estar exposta a estressores "verticais" (também chamados transgeracionais) ou "horizontais" (desenvolvimentais). Os estressores verticais incluem padrões, mitos, tabus, expectativas, segredos e legados transmitidos de geração a geração. Já os estressores horizontais estão relacionados às transições do ciclo vital e incluem tanto os eventos previsíveis, inerentes à passagem de uma etapa do ciclo vital para outra, quanto os imprevisíveis, que podem romper o processo de ciclo de vida, tais como morte prematura, enfermidade crônica, nascimento de criança deficiente, entre outros.

Para fins deste estudo, será considerado se os estressores relacionados a perdas por morte e a separações dos pais têm relação com a facilidade ou dificuldade de adaptação 
da criança à escola de educação infantil. Para tanto, buscou-se subsídios na teoria do apego de Bowlby (1969/ 1990a, 1973/1990b, 1980/1990c) pelo fato de o autor ter expandido a visão do desenvolvimento para além dos processos intrapsíquicos, e por referir-se a perdas e separações reais. De acordo com Bowlby (1980/1990c), a forma como a pessoa se separa de alguém é diretamente proporcional ao seu apego a esta pessoa. $\mathrm{O}$ autor entende que a experiência mais dolorosa que se pode sofrer é a perda real da pessoa amada e acrescenta que a família tem importância fundamental na elaboração do processo de luto infantil, principalmente pela forma como notifica e esclarece as dúvidas infantis. Assim, segundo o autor, experiências de perda e separação na família estarão sempre relacionadas ao apego pré-existente entre a criança e seus cuidadores.

Conforme afirmam Carter e McGoldrick (1989/1995), quando a morte for acidental e inesperada (estressor horizontal ou imprevisível), aquela que foge ao ciclo vital familiar, os efeitos parecem ser ainda mais intensos no desenvolvimento infantil. Segundo Brown (1995), a morte de um progenitor, quando os filhos são pequenos, pode trazer conseqüências disfuncionais para gerações posteriores, com rupturas familiares e prejuízos no estabelecimento de novos sentimentos de intimidade.

Para Bromberg (1994), o significado dado à morte pela criança varia de acordo com a idade, seu momento de desenvolvimento psicológico, a forma como os adultos lidam com a perda e a qualidade da sua relação anterior com a pessoa falecida. Em momentos de perdas e separações, acrescenta a autora, importa o respaldo encontrado na rede de apoio social e familiar.

Sobre a separação conjugal, Andolfi e Angelo (1988) entendem que ela implica, sempre, em uma reestruturação profunda, não apenas dos cônjuges envolvidos, mas dos filhos, das famílias de origem e de toda a rede social envolvida. Balaban (1985), especialista em educação infantil, refuta o mito de que filhos de pais separados tenham mais dificuldades de adaptação ao ambiente escolar, embora atente para o fato de que a entrada na escola possa reviver experiências recentes de abandono e perda.

Com o propósito de mapear as configurações familiares de crianças que estão iniciando sua vida escolar, buscando identificar os estressores, principalmente aqueles relacionados a perdas e separações familiares, bem como os relacionamentos existentes entre as famílias atual e de origem, optamos pela representação da família em três gerações. O genograma nos pareceu ser um instrumento que se presta à coleta de dados pretendida, além de ser compatível com a perspectiva da teoria sistêmica familiar, abordagem teórica deste estudo.

O genograma é a representação gráfica (através de símbolos que incluem basicamente círculos, quadrados e linhas) da composição familiar e dos relacionamentos básicos em, pelo menos, três gerações (Carter \& McGoldrick, 1989/1995). Ele permite, de uma forma rápida e clara, visualizar quais são os membros que constituem a família, tenham eles vínculos consangüíneos ou não, identificando a idade e ocupação (profissão/escolaridade) de cada pes- soa, além de retratar o lugar ocupado por cada um dentro da estrutura familiar.

Através do genograma, pode-se saber qual é a família atual do sujeito (paciente identificado), qual a situação dos casais (se ocorreu separação, divórcio ou concubinato e há quanto tempo foi). Pode-se, ainda, constatar a ocorrência de adoção, aborto, natimorto ou nascimento de gêmeos. Também podem ser identificadas as doenças sérias e as pessoas já falecidas, sendo registrado o ano e o motivo de cada morte. Outras informações relevantes podem ser incluídas no genograma, tais como a procedência das pessoas, data de migração, a ocorrência de alcoolismo, obesidade, uso de drogas, encarceramento, aposentadoria, entre outros.

Quanto aos padrões de interação familiar, segundo a classificação de Carter e McGoldrick (1989/1995), podese registrar, através do genograma, a ocorrência de relacionamentos muito próximos, relacionamentos conflituados, relacionamentos distantes, rompimentos, desavenças ou relacionamentos fusionados e conflituados, entre duas ou mais pessoas. Entendemos que a qualidade dos vínculos estabelecidos entre os familiares das crianças em período de adaptação escolar e destes com a sua família de origem pode garantir maior estabilidade neste momento de transição do ciclo vital.

Neste estudo, o que se pretende é ilustrar a utilização do genograma como um instrumento de pesquisa para analisar o impacto de estressores horizontais, especialmente perdas e separações, na transição família-escola. Baseado em uma dissertação de mestrado (Castoldi, 1997) que investigou a história de perdas e separações na família e a adaptação da criança à escola de educação infantil, o genograma será utilizado com os seguintes objetivos: caracterizar as configurações familiares, identificar eventos estressores no ciclo vital das famílias, em especial, as perdas e separações na família atual e na família de origem, e analisar os padrões de relacionamento na família atual e entre esta e a família de origem.

\section{Método}

\section{Participantes}

Foram selecionados, entre 94 alunos de três diferentes turmas de educação infantil de uma escola da rede pública estadual da periferia de Porto Alegre, 3 alunos que se adaptaram facilmente à rotina escolar, sendo um de cada turma, e 3 alunos que revelaram mais dificuldades ao se adaptar, e suas respectivas famílias. A escolha dos alunos, para cada um dos dois grupos, foi baseada num acordo consensual entre as três professoras e as pesquisadoras, após um período de observação. No grupo de alunos com dificuldades de adaptação encontram-se dois alunos (Léo Gabriel e Bárbara) selecionados por sua conduta agitada, agressiva e sem limites e uma aluna (Suelen) escolhida por sua rigidez, tristeza, apatia e alheamento. Em comum, destaca-se o fato de todos os alunos apresentarem dificuldades em adaptar-se à rotina da escola, com baixo aproveitamento das atividades e prejuízo no vínculo com o grupo de colegas. Os alunos com facilidade de adaptação 
formaram vínculo rapidamente com os colegas e a professora, adequaram-se à rotina escolar e mostraram-se satisfeitos com o ambiente escolar.

\section{Delineamento e Procedimentos}

Foi realizado um estudo de casos coletivo (Stake, 1994), com o objetivo de compreender os casos extremos de boa e má adaptação à escola de educação infantil, selecionados a partir dos critérios previamente definidos pelas professoras e pelo grupo de pesquisadores, através das observações realizadas durante o período de adaptação. Tal período compreendeu os 23 dias úteis do primeiro mês letivo do ano; a observação iniciava-se 15 minutos antes do início da aula, quando os pais ou familiares permaneciam com as crianças no pátio, o momento da "entrega" dos fillhos à professora, e momentos diversos da rotina escolar (hora da rodinha, do lanche, da higiene, do pátio...), somando 30 minutos diários de observação por turma.

$\mathrm{Na}$ coleta de dados (entrevistas com as seis mães e acompanhamento do período de adaptação das crianças), trabalharam três pesquisadoras previamente treinadas, pois as entrevistas com as mães e as observações em sala de aula aconteceram simultaneamente, nas três turmas de educação infantil. As pesquisadoras registravam as observações, mas desconheciam os critérios utilizados para a classificação do grupo bem ou mal adaptado, estando, portanto, "cegas" quanto aos objetivos do estudo.

\section{Instrumentos}

Foi utilizado o Genograma Familiar que teve como objetivo avaliar a configuração familiar, verificar a ocorrência de eventos estressores com ênfase nas perdas e separações, e avaliar os padrões de relacionamento entre a família atual e a família de origem. As mães foram solicitadas a identificar as pessoas que faziam parte da família, referindo a idade e ocupação de cada um, destacando as pessoas falecidas e a situação conjugal. Também deveriam identificar eventos estressores ligados a perdas e separações. Foi-lhes solicitado, ainda, que destacassem os relacionamentos especiais de proximidade ou conflito entre os familiares. Para análise do genograma foram utilizadas as convenções propostas por McGoldrick e Gerson (1985).

\section{Resultados}

Os resultados deste estudo serão apresentados em duas etapas. Inicialmente, será apresentada a análise do genograma de cada caso. A seguir, serão analisados, conjuntamente, três casos de boa adaptação (Casos 1, 2 e 3) e de má adaptação à escola de educação infantil (Casos 4, 5 e 6).

Os nomes das pessoas foram alterados, por questões éticas. Procurou-se, no entanto, manter as semelhanças de iniciais entre familiares e o uso de nomes simples ou compostos, quando era o caso.

\section{Caso 1}

Rafael, de 5 anos e 7 meses, é o mais novo de dois irmãos, filhos de Reinaldo, 33 anos, segundo grau, supervisor de vendas e Rosane, também de 33 anos, segundo grau completo, que trabalha como gerente comercial. O casal tem mais uma filha, Rafaela, de 10 anos, que cursa a quinta série.

O genograma familiar, tal como se apresentava no momento em que foi realizada a entrevista, é apresentado na Fig. 1.

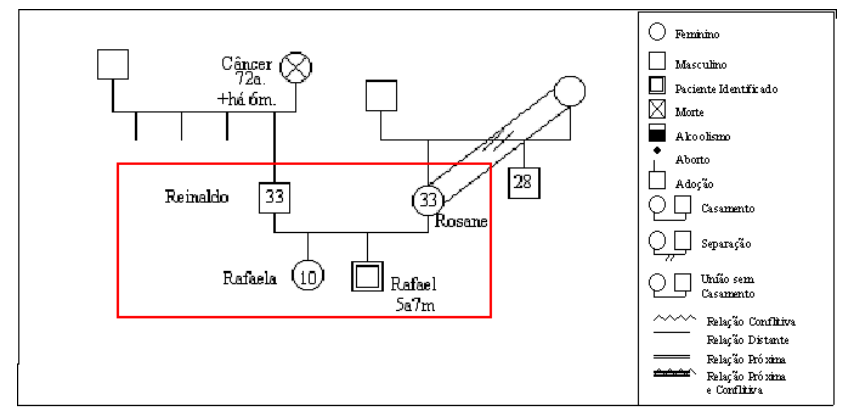

Figura 1. Genograma familiar do caso 1.

Rose, como prefere ser chamada a mãe, nasceu no sul, e mudou-se para São Paulo aos seis anos, após o nascimento do seu único irmão, devido ao trabalho do pai. Enfrentou a separação dos pais quando tinha 12 anos, voltando com a mãe e o irmão para Porto Alegre. Morou com a mãe até se casar, mas como já trabalhava e era independente, conta que não sentiu dificuldades em adaptar-se ao casamento.

Reinaldo, o pai, é o mais novo de quatro filhos e também morou em casa até se casar. No início do ano perdeu sua mãe, aos 72 anos, de "câncer fulminante", fato que abalou toda a família. Em função da doença da avó, o pai de Rafael teve que deixar o emprego, para revezar-se com os irmãos nos cuidados hospitalares.

Em um contato posterior, quando o Rafael já se mostrava adaptado à rotina escolar, a mãe relatou que o pai fez um surto depressivo, após a morte da sua mãe (avó de Rafael), precisando ser hospitalizado. Em função da doença, o marido ficou bastante envolvido com seu pai e parou de trabalhar, sendo, portanto, ela quem sustenta a casa.

A análise do genograma revela a repetição da configuração da família de origem da mãe, na família atual: casal e dois filhos, com uma diferença de 5 anos entre si, sendo a menina a filha mais velha, e o menino o mais jovem. Esta repetição é percebida pela mãe, quando comenta que os filhos têm a mesma diferença de idade que ela e seu irmão. Percebe-se, ainda, um forte vínculo entre a família atual e a família de origem materna. A mãe e o irmão moram próximos, e, juntos com a avó materna, constituíram uma empresa familiar, onde todos trabalham. O marido não estava incluído nesta empresa, mesmo quando morava em casa.

Trata-se de uma família tipicamente nuclear, formada pelo casal e dois filhos, conforme retrata o genograma. As avós aparecem como pessoas fortes e queridas, com quem a família estabelece bom vínculo. Já a figura do avô, mesmo o que ficou viúvo recentemente, não foi referida. 
Castoldi, L., Lopes, R.C.S., \& Prati, L.E. (2006). O Genograma como Instrumento de Pesquisa do Impacto de Eventos Estressores na Transição Família-Escola.

\section{Caso 2}

Aline, 5 anos e 11 meses, é a mais nova de quatro filhos, tem um irmão de 11 anos, na quarta série, na mesma escola, um irmão de 16 anos, na quinta série, e uma irmã de 17 anos, que está em casa. João, o pai, tem 42 anos, é pedreiro, e a mãe, Maria, tem 36 anos e trabalha como copeira.

O genograma apresentado na Fig. 2 retrata a configuração familiar existente no momento da entrevista.

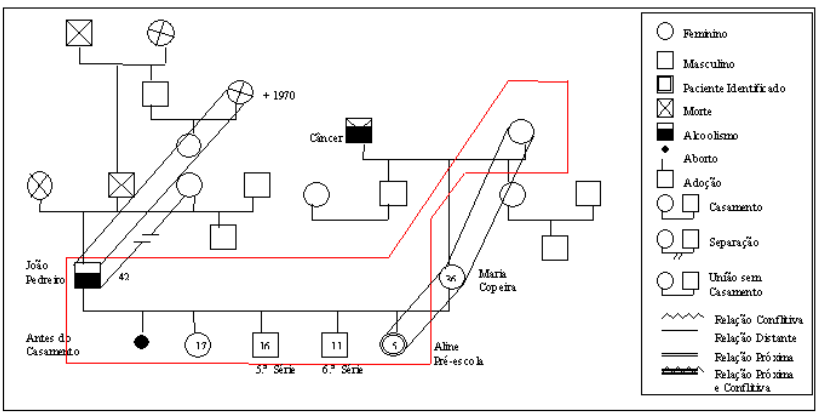

Figura 2. Genograma familiar do caso 2.

Maria é a segunda de uma família de três filhos: tem um irmão mais velho, que mora com uma companheira, e uma irmã mais moça, casada, com um filho. Há um ano, Maria perdeu o pai, que era alcoolista, por câncer desencadeado por uma intoxicação com agrotóxico.

João morou com os pais naturais até dois anos. De família muito humilde, conta que vivia "atirado", como menino de rua. Aos dois anos foi oficialmente adotado por um casal de origem alemã, que não possuía filhos. Poucos meses antes da morte da madrasta, o pai engravidou outra mulher. Nesta época, João não morava mais com os pais adotivos, teve problemas de relacionamento com eles, e foi morar com uma tia a partir dos seus 11 anos. Aos 16 anos esta tia faleceu, fato que abalou muito João. Ele continuou morando com a filha desta tia, ajudando no sustento da casa, até se casar, aos 24 anos.

Durante o período de namoro Maria engravidou e, como não tinham condições de se casar, ela induziu o aborto com uso de chás. Após o casamento, com a situação financeira mais definida, tiveram os quatro filhos.

Trata-se de uma família nuclear, na qual a aluna é a caçula de quatro filhos. A configuração familiar aproximase mais do modelo da família materna, conforme pode-se observar no genograma. Também neste caso aparece um padrão de repetição nas duas gerações, pela escolha de maridos alcoolistas. Tal como no caso anterior, a avó materna mantém um vínculo muito próximo com a neta em questão, mostrando integração entre a família atual e a família de origem, da parte materna.

\section{Caso 3}

Renan, 6 anos e 1 mês é o único filho de José, 35 anos, segundo grau, maquinista e de Regina, 38 anos, primeiro grau incompleto, do lar, e nasceu 7 anos após o casamento.

O genograma apresentado na Fig. 3 retrata a configuração familiar obtida no momento da entrevista.

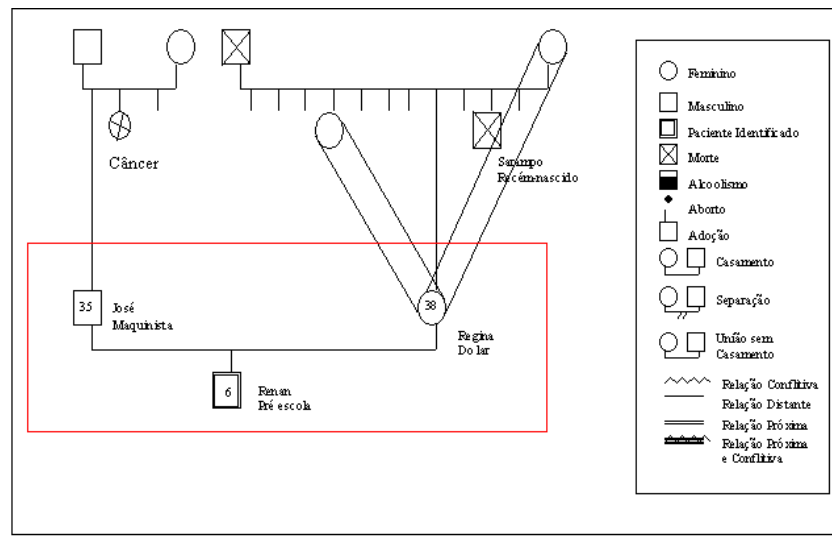

Figura 3. Genograma familiar do caso 3

A mãe é a oitava de 12 filhos e recorda que, na infância, era muito arteira, não queria estudar. Perdeu o pai aos 6 anos, sendo criada pela mãe e os irmãos. Quando adolescente, mudou-se com uma irmã, que se casou. Não achou difícil sair de casa. Aos 26 anos, casou-se com José, com quem teve o Renan. Conta que a família sofreu muito com a perda de uma cunhada, há três anos, a primeira experiência de morte, depois de adulta. Este ano, sua mãe mudou-se do interior, para a capital, seu sogro se aposentou e o Renan, que freqüenta creche desde os três anos, trocou de escola, para cursar a educação infantil.

Também neste caso trata-se de uma família nuclear, desta vez formada pelo pai, a mãe, e o único filho. A família nuclear segue um modelo mais próximo da família paterna, de três filhos; na família da mãe, também nuclear, eram 12 filhos, que vivenciaram a morte do pai ainda pequenos. $\mathrm{O}$ relacionamento familiar aparenta ser bom, a mãe destaca nunca ter ficado separada do filho ou do marido, exceto por motivos de trabalho, quando este viaja. Parece existir uma boa relação entre a mãe e a avó.

\section{Síntese dos Casos de Adaptação Fácil à Escola de Educação Infantil}

Nos três casos que se destacaram pela facilidade das crianças em adaptar-se à escola, os alunos possuíam a mesma faixa de idade (com variação de 5 meses) e dois deles não tinham experiência prévia de escolaridade formal, apenas Renan (Caso 3) freqüentara creche por 3 anos.

Cabe destacar que neste pequeno grupo de crianças bem ajustadas à escola nenhuma experienciou a separação dos pais. Igualmente, nenhum destes alunos sofreu perda na família atual, todos têm contato com o pai, a mãe e os irmãos. Já em relação à família de origem, os três alunos perderam um dos avós e um aluno perdeu uma tia. Embora tenha sido destacado o forte vínculo das crianças com os avós (em todas estas famílias, as avós apareceram como figuras importantes, com quem os pais estimulavam o contato e a proximidade afetiva), aparentemente, estas perdas não interferiram no processo de adaptação destas crianças à escola.

Nas famílias de origem, apareceram histórias de perdas e separações importantes. Por exemplo, nos Casos 1 e 2 houve separação, morte e/ou abandono por parte dos pais. 
O Caso 2 é um caso de adoções múltiplas por parte do pai. No último Caso (3), a mãe foi criada sem seu pai, desde os seis anos de idade. Estas famílias, entretanto, buscaram algum tipo de compensação pelas perdas, separações ou abandonos, através da família atual, valorizando a união familiar. Isto ficou especialmente evidente nos Casos $1 \mathrm{e}$ 2. Chamou a atenção, também, o vínculo próximo com a família de origem, especialmente com as avós, do lado materno, em todos os casos.

A facilidade com que as três crianças adaptaram-se ao contexto escolar foi confirmada pelo parecer das professoras, ao final do ano, que revelou que todas elas apresentaram um bom aproveitamento das atividades letivas, destacando-se por sua criatividade, colaboração e relacionamento interpessoal. Nenhuma delas apresentou qualquer dificuldade quanto à conduta, relacionamento ou aquisições de conhecimentos. Ao final do ano letivo, todos foram considerados aptos a freqüentar a primeira série.

\section{Caso 4}

Léo Gabriel tem 5 anos e 6 meses e é o único filho do segundo casamento da mãe, Tereza Maria, 45 anos, do lar, com Léo Batista, de 50 anos, motorista. Anteriormente, Tereza fora casada durante sete anos com Carlos, com quem teve dois filhos: Marcos e Marcelo, atualmente com 15 e 11 anos.

A Figura 4 retrata a configuração da família, no momento da entrevista.

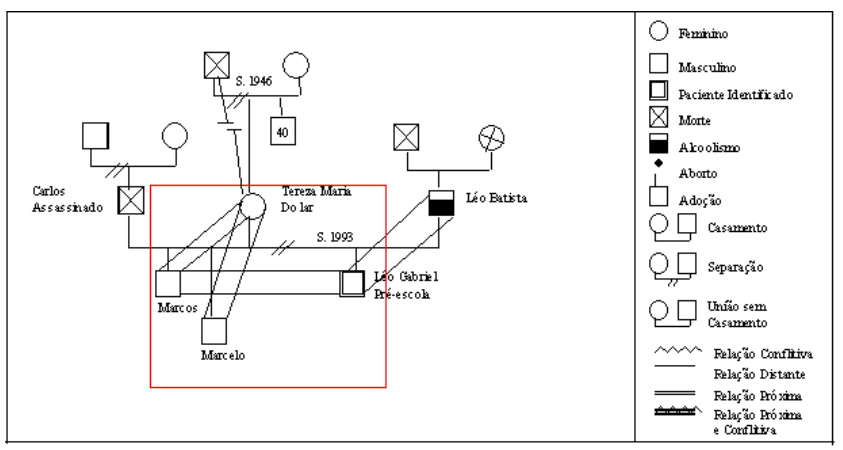

Figura 4. Genograma familiar do caso 4 .

Tereza é a mais velha de dois filhos; quando estava com 5 anos, o irmão nasceu e, em seguida, os pais se separaram. Foi criada apenas pela mãe, que não voltou a se casar. Quando o pai de Tereza morreu, ela estava com 15 anos e mantinha um relacionamento distante com ele. Morou com a mãe até se casar, grávida, aos 29 anos. Conta que a mãe aceitou com facilidade o casamento com Carlos. Ela já trabalhava fora de casa desde os 17 anos, e o casal permaneceu morando no mesmo terreno até o nascimento do segundo filho, quando, então, mudaram-se de bairro.

O pai dos meninos foi assassinado, durante uma briga de vizinhos, há nove anos, quando os filhos tinham dois e seis anos. Após a inesperada morte do marido, Tereza permaneceu morando sozinha com os filhos. Mãe e filhos tiveram atendimento psicológico. Passados dois anos, e alegando que os meninos pediam um "novo pai", Tereza casou-se com Léo Batista. Desta união, nasceu Léo Gabriel. O casamento durou cerca de cinco anos, terminando devido aos desentendimentos de Léo Batista com os filhos do primeiro casamento, e pelo seu uso abusivo de álcool.

No ano em que os pais se separaram, aos 2 anos de idade, Léo Gabriel já freqüentava a creche, onde permaneceu até o último ano. Nesta instituição, o menino apresentou diversos problemas de conduta, chegando a cair de uma janela, no segundo andar do prédio, necessitando hospitalização para avaliação neurológica. Este ano, mudou para a mesma escola onde estudaram os irmãos, para iniciar a educação infantil.

Esta família é marcada pela ausência paterna, que tem início na família de origem da mãe. A perda e a busca de um pai aparecem com freqüência no depoimento materno. Pode ser destacado o tratamento diferenciado para com o filho mais novo, que se torna explícito no depoimento materno, quando esta se refere ao menino como "este aqui", "o guri” ou "em termos de Léo Gabriel”. Léo Gabriel é fruto do segundo casamento, sem sucesso, de Tereza. Nascido após um momento traumático para a família, pelo assassinato do pai dos seus irmãos, o menino também carrega o peso de ter um pai alcoolista. Do pai, Léo Gabriel é o único fillho. Com a mãe, divide espaço junto aos dois irmãos mais velhos, "que não dão trabalho, apesar de tudo o que viveram", e que se destacam em atividades escolares e esportivas. Sem dúvida, Léo Gabriel não é o "filho ideal", assim como o segundo marido também não foi o "pai ideal" para os dois primeiros filhos.

O genograma retrata uma família que foi reconstituída, mas que atualmente é uniparental, com ausência da figura paterna (a mãe ficou viúva do primeiro casamento e está separada do segundo marido). A análise do genograma mostra a repetição da ausência da figura paterna, uma vez que seus pais separaram-se quando ela estava com 5 anos, e sua mãe optou por criar os filhos sozinha. Na família atual, aparece uma distorção nos papéis, pela ausência da figura paterna, fazendo com que o irmão mais velho, aos 15 anos, assuma a autoridade do pai, junto aos mais jovens.

Quanto ao momento do ciclo vital, trata-se de uma família com filho pequeno e com filhos adolescentes; os conflitos referentes à educação infantil de Léo Gabriel parecem trazer mais transtornos que a própria adolescência dos filhos maiores. Embora apareça um vínculo de dependência de Tereza com sua mãe, com quem morou até os 29 anos (ou de cuidado, uma vez que a avó era sozinha), pelo relato, nesta entrevista, não é possível avaliar o relacionamento entre a família atual e a de origem.

\section{Caso 5}

Bárbara, 5 anos e 8 meses, é a única filha de Maria Aparecida, 31 anos, segundo grau, professora e Clóvis, taxista, falecido há dois anos.

A figura 5 mostra como estava configurada a família, no momento da entrevista. 
Castoldi, L., Lopes, R.C.S., \& Prati, L.E. (2006). O Genograma como Instrumento de Pesquisa do Impacto de Eventos Estressores na Transição Família-Escola.

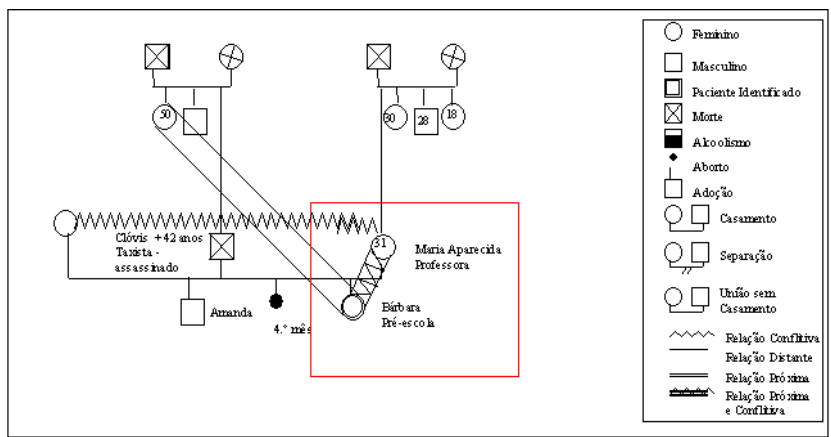

Figura 5. Genograma familiar do caso 5

Maria Aparecida é a mais velha dos quatro filhos de Gabriel e Jurema. Morou com os pais em Porto Alegre até perder a mãe, há dez anos. Após a morte da mãe, o pai, viúvo, mudou-se com os filhos para o Rio de Janeiro, porque lá moravam outros familiares. Permaneceram por 12 anos lá, e agora, há seis meses, quase 4 anos após a morte do pai, os filhos retornaram para Porto Alegre.

No Rio, Aparecida começou a namorar o Clóvis, um rapaz mineiro, que estava passando as férias no local. Quando Aparecida o conheceu, Clóvis já tinha perdido o pai e a mãe, e vivia com os dois irmãos mais velhos, hoje com quase 50 anos, ambos solteiros. A família de Aparecida era muito rígida. Assim, após um período de namoro "vigiado", os dois noivaram e se casaram. A gravidez de Bárbara foi planejada e ocorreu quase três anos após o casamento, seguindo um abor to espontâneo, no quarto mês de gestação.

O casal sempre trabalhou fora; o pai sustentava a casa e Aparecida mantinha as despesas com a filha. Lembra que o marido nunca comprava nada para a menina, mas esta era muito apegada a ele. Há quatro anos, morreu o pai de Aparecida, único avô de Bárbara, mas os filhos continuam morando no Rio.

Há dois anos, o pai da menina foi assassinado, após um assalto durante o trabalho. Clóvis estava com 43 anos e Bárbara, com 3 anos; fazia seis anos que ele e Aparecida estavam casados. Aparecida não tinha recursos sequer para providenciar o enterro do marido. Conta que quem a auxiliou foi a equipe de professores e os pais dos alunos da escola onde trabalhava.

Passados quinze dias da morte do marido, Aparecida descobriu que ele tinha outra família: uma mulher e uma filha, pouco mais velha que a Bárbara, registrada em cartório. Como o pai não deixou pensão, esta família vem requerer a partilha dos móveis e bens da casa de Aparecida. Devido às constantes visitas inoportunas desta mulher, e pelo alto custo de vida, Aparecida retorna com Bárbara para o sul. Compra um pequeno apartamento, com o dinheiro da rescisão do seu contrato de professora, e tenta recomeçar a vida. Atualmente está desempregada, tem dificuldade de procurar emprego, por não ter com quem deixar a menina, e alega enfrentar muita discriminação devido à sua cor negra. Bárbara está agitada, apresenta enurese noturna e revela, algumas vezes, desejar morrer, para reencontrar o pai.
Esta é uma família uniparental, como no caso anterior, formada pela mãe e sua única filha, Bárbara. O assassinato do pai, durante o trabalho como taxista, caracteriza um evento estressor imprevisível, e um momento de crise dentro do ciclo vital desta família, ainda em fase de reestruturação. É uma família pequena, sem rede de apoio. Da família de origem, restam apenas os tios, irmãos de Aparecida, todos em dificuldades financeiras, que, embora mantenham vínculo afetivo, não têm possibilidade de dar apoio às duas.

Da história familiar, deve-se destacar a história de perdas, separações e mudanças. Quando Aparecida perdeu a mãe, ainda solteira, enfrentou a mudança de estado e de cultura. Durante o casamento, ocorreu a perda de um bebê, no quar to mês de gestação, e a perda do pai. A morte inesperada do marido há quase dois anos, novamente determinou a mudança de cidade, além da queda no padrão de vida da família, da perda do emprego da mãe e da descoberta de que não era sua única esposa. Para Bárbara, a perda do pai acarretou na mudança de escola, na perda dos amigos e do espaço de exclusividade junto à memória de um pai querido e idealizado, de quem acreditava ser exclusiva, no lugar de filha.

É importante considerar que a situação atual da família é difícil, especialmente pelo desemprego da mãe e pela fal ta de uma rede de apoio para esta pequena família. Quando a mãe comparece à escola, seu relato é de um sofrimento sincero de quem precisa recomeçar a vida, com uma filha pequena, e não encontra apoio. Por outro lado, percebe-se que ela é resistente em aceitar sugestões e conselhos vindos da escola, e chega a pensar na institucionalização da filha, em um semi-internato, como sua única solução para retornar ao trabalho.

\section{Caso 6}

Suelen nasceu em 06/05/90, e estava com 5 anos e 10 meses no início do ano letivo. É a primeira filha de Dirceu, 24 anos, primeiro grau, borracheiro, falecido há um ano e de Tânia, 23 anos, primeiro grau incompleto, auxiliar de enfermagem. A mãe teve um segundo casamento, com Júlio, 24 anos, do qual nasceram Júlia, de 4 anos e Juliana, de 2 anos.

A configuração familiar no momento da entrevista é apresentada na Figura 6.

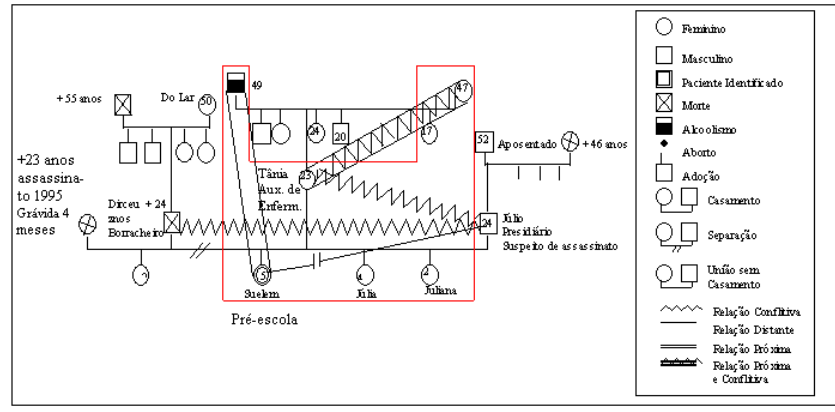

Figura 6. Genograma familiar do caso 6. 
Suelen é a única filha do casamento de Tânia com Dirceu. O casal namorava há algum tempo, contra a vontade de ambas as famílias. Tânia é a terceira de seis filhos; Dirceu tinha mais quatro irmãos. Quando ela estava com 15 anos e ele 17, fugiram de casa para se casar. Ela engravidou e o casamento terminou logo após o nascimento de Suelen, devido ao fato de ele não deixá-la trabalhar fora e ter sua independência.

Pouco tempo depois, Tânia reencontrou Júlio, um excolega de escola, e passou a viver com ele. Desta união nasceu a Júlia, e, dois anos após, a Juliana. Durante este casamento, Suelen permaneceu morando com os avós. Segundo a mãe, esta foi uma opção da própria menina que não aceitava o Júlio, preferindo morar com seu avô ou com seu pai. Suelen tornou-se uma menina calada e nervosa. Após o nascimento da terceira filha, e, com a intenção de reunir as três meninas, Tânia separou-se de Júlio, retornando à casa paterna.

Há um ano, enquanto Tânia viajava, em férias, com as duas meninas menores, Dirceu foi assassinado, juntamente com sua nova companheira, grávida de quatro meses, e um amigo do casal. O crime ocorreu na borracharia, ao lado da casa dos avós, onde estava Suelen. A menina viu o pai baleado, com o corpo estendido no chão. Testemunhas teriam visto o autor do crime: Júlio, que está preso, acusado pelo assassinato.

Até o início da educação infantil, Júlio permanecia na prisão, Tânia não queria mais contato com ele. Mãe e filhas continuam morando com os avós; o avô materno passou a fazer uso abusivo de álcool e Suelen dormia com a foto do pai embaixo do travesseiro.

A análise da configuração familiar indica uma família que foi uniparental (por morte do pai), passou a reconstituída e que novamente é uniparental, com a ausência da figura paterna (pela separação do casal). Chama a atenção o fato de a mãe identificar-se como "viúva" e não como estando separada do segundo marido.

A análise do genograma aponta um relacionamento conflituado com o segundo marido e um vínculo muito próximo e conflituado com sua mãe, que a espancou até a gravidez da Suelen, mas de quem ela nunca conseguiu separar-se, entregando-lhe, inclusive, a educação desta filha. Aparece um tratamento claramente diferenciado da mãe para com as filhas do segundo casamento, o que se confirma em seu depoimento (por ex. quando diz que estava viajando "com as minhas filhas", a Suelen não estava incluída). Pode-se supor que o vínculo mais consistente de Suelen, uma vez que o pai está morto, seja com o avô materno (que é alcoolista) - ela preferiu morar com o avô a conviver com o segundo marido da mãe.

Da situação familiar atual, percebe-se que a Suelen ainda passa pelo processo de luto pelo pai; o avô é quem vem para as reuniões da escola, apesar de ser descrito como alcoolista pela mãe. Em contatos posteriores, ficou-se sabendo que Tânia novamente tenta refazer sua vida, tendo se mudado com as duas meninas mais novas. Outra vez, Suelen encontra-se aos cuidados dos avós.
Síntese dos Casos de Adaptação Difícil à Escola de Educação Infantil

Das histórias familiares dos casos cujos alunos apresentavam dificuldades de adaptação, deve ser destacada a história de separação conjugal e a ausência paterna, a qual, em dois casos, ocorreu devido ao assassinato do pai. Foi o que ocorreu com a Bárbara (Caso 5), que teve o pai assassinado enquanto trabalhava, no Rio, como taxista, e que, com sua morte, teve que mudar de cidade, conviver com a mãe desempregada, aceitar a queda na qualidade de vida, além de aceitar o fato de que o pai tinha outra esposa e outra filha de sua idade. Suelen (Caso 6) também enfrentou uma perda traumática, ao presenciar o pai "com o corpo forrado de bala", depois de ter sido assassinado pelo segundo marido de sua mãe; antes de perder o pai, teve que se acostumar às ausências freqüentes da mãe, que se mudou com as irmãs menores, quando se casou pela segunda vez, deixando-a aos cuidados dos avós. Léo Gabriel (Caso 4) não perdeu o pai, o qual está apenas separado de sua mãe, por ser alcoolista, mas a família carrega a marca do assassinato do primeiro marido da mãe, pai de seus irmãos, ocorrida após uma briga de vizinhos.

A situação atual das três famílias também apresenta particularidades: as famílias de Suelen e Bárbara ainda estão vivendo o período de luto pela morte dos pais; ambas as mães buscam redefinir suas vidas profissionais e afetivas, e mostram-se um pouco afastadas emocionalmente de suas filhas. Na família de Léo Gabriel, um dos irmãos, que se destaca em atividades esportivas, está prestes a viajar para as Olimpíadas, um evento que tem mobilizado toda a família.

Deve ser destacado o fato de que, nestas famílias, apareceu uma incidência maior de eventos estressores na família atual, tais como: mudança de cidade, troca de emprego ou desemprego dos pais, alcoolismo ou encarceramento de pessoas que tiveram contato próximo com a família.

Quanto ao vínculo destas famílias com as famílias de origem, em contraste com o grupo anterior, não foram observados vínculos de proximidade das mães com suas próprias mães. No Caso 4, não foi feita nenhuma referência especial ao vínculo com a avó materna; no Caso 5, a avó materna havia falecido e, no Caso 6 havia uma relação muito conflituosa e ambivalente da mãe com a sua mãe. Neste último, parecia haver um vínculo de mais confiança da aluna com o avô paterno do que com a própria mãe, apesar de ele ser alcoolista. Isto se confirma pelo fato de ter sido ele a pessoa que acompanhou a Suelen durante o período de adaptação.

Com relação à história de perdas na família de origem, observaram-se perdas dos avós paternos nos Casos 4 (ambos), 5 (ambos) e 6 (pai). Do lado materno, observaram-se perdas de ambos os avós no Caso 5. Nenhuma destas perdas, no entanto, receberam atenção especial nos depoimentos das mães. Somente no primeiro caso (Caso 4) houve separação conjugal na família de origem, no lado materno, com conseqüente abandono pelo pai, quando ela estava com 5 anos. 


\section{Discussão}

Através da análise dos genogramas das famílias foram percebidas diferenças importantes entre os grupos de alunos com adaptação fácil e difícil à escola de educação infantil quanto às perdas e separações reais na família. A ausência de história prévia de separação dos pais curiosamente foi encontrada apenas no grupo de crianças que se ajustaram bem à escola. As crianças com adaptação fácil não enfrentaram perdas por morte em suas famílias atuais, nem experienciaram a separação dos pais, enquanto nos três casos de adaptação difícil ocorreram experiências extremas de perda, sendo que dois destes alunos perderam o pai por assassinato há menos de dois anos, e outro aluno vivenciou o assassinato do primeiro marido da mãe, pai de seus irmãos.

Já em relação a perdas na família de origem, não foram constatadas diferenças, visto que alunos dos dois grupos sofreram perdas de familiares, geralmente os avós. A morte violenta e inesperada caracteriza o que Carter e McGoldrick (1989/1995) denominaram de "estressor horizontal": um evento imprevisível que justifica a disfuncionalidade da família, podendo gerar um grande rompimento no equilíbrio do sistema familiar.

É importante analisar o contexto familiar em que ocorreram estas perdas, bem como as repercussões das mesmas para o funcionamento familiar. Léo Gabriel enfrenta a falta do pai (pela separação do casal), em uma família que experenciou o assassinato do primeiro marido da mãe, pai de seus dois irmãos, estes idealizados pela mãe; sua dificuldade de adaptação à escola pode ser entendida como uma forma de delimitar seu espaço na sala de aula, provavelmente para compensar a sua falta de espaço na família. Para Bárbara, a perda do pai foi real e traumática (assassinato), e acarretou a mudança de cidade, as dificuldades financeiras, o desemprego e a desestruturação da mãe, reforçados pela falta de uma rede familiar que apoiasse mãe e filha; a dificuldade de adaptação da menina parece estar em sintonia com sua situação familiar atual. Também Suelen enfrentou a perda real do pai por assassinato, com o agravante de não ter estabelecido uma relação de apego forte e adequada com a mãe (morava com os avós, ele alcoolista, ela agressiva); suas dificuldades de adaptação parecem estar associadas ao luto pelo pai, sua principal figura de apego e, com tanta tristeza, a escola não parece suficientemente atrativa para um novo investimento afetivo.

A análise dos padrões de relacionamento entre a família atual e de origem possibilitou a visualização das triangulações entre as famílias atuais e as famílias de origem, principalmente quanto ao relacionamento das mães com as avós. Para os teóricos da terapia familiar sistêmica, o triângulo é a forma básica de relacionamento familiar. Para Bowen (1979/1991), em situações de tensão, como nas perdas e separações, as alianças entre os familiares, que normalmente oscilam de uma pessoa para outra, podem acarretar o privilégio de alguma pessoa em detrimento de outras.

Examinando as relações estabelecidas com as famílias de origem observou-se um vínculo diferente entre as fa- mílias atuais e de origem, nos dois grupos. No grupo de adaptação fácil os avós apareceram como pessoas importantes, com quem a família estabelecia um vínculo de proximidade afetiva, sendo as mães ajudadas por suas mães. Nas famílias cujos filhos apresentaram dificuldades de adaptação, os avós geralmente apareciam como pessoas distantes ou ausentes e a família atual, na maioria dos casos formada apenas pela mãe e os filhos, refletia a carência de uma rede de relações familiares que a apoiasse.

Quanto à presença de eventos estressores, através do genograma observamos que nos dois grupos apareceram situações familiares difíceis, na época das entrevistas, tais como: doenças graves dos pais, alcoolismo, troca de emprego ou residência, mas a incidência de estressores familiares foi maior nos casos de adaptação difícil.

\section{Considerações Finais}

Este estudo teve o propósito de ilustrar a aplicabilidade do genograma na pesquisa em psicologia do desenvolvimento, especificamente no estudo da família cujos filhos encontravam-se em processo de adaptação à educação infantil. O genograma possibilitou a análise das configurações familiares, facilitou a identificação de eventos estressores no ciclo vital das famílias, em especial, as perdas e separações, e a análise dos padrões de relacionamento na família atual e entre esta e a família de origem.

Observamos que a ocorrência de eventos estressores imprevisíveis, tais como a morte violenta de um dos pais, associada à carência de vínculos de proximidade afetiva nas famílias atual e de origem, marcaram as histórias das crianças com dificuldades de adaptação à pré-escola. A separação conjugal dos pais não pareceu estar associada à melhor ou pior adaptação, mas, em qualquer configuração familiar, a existência de uma rede de apoio efetiva, e de vínculos familiares de proximidade indicaram uma transição mais fácil entre a família e a escola. Destacamos o fato de que as crianças com facilidade de adaptação tinham sempre o mesmo adulto (mãe, pai ou avó) como referência nas horas de chegar e sair da escola.

Entendemos que uma das contribuições deste trabalho foi o seu caráter transdisciplinar, ao trazer um instrumento originariamente utilizado na clínica sistêmica familiar para a pesquisa em psicologia do desenvolvimento. P. Minuchin (1985) acreditava que a psicologia do desenvolvimento e a terapia familiar tinham muitas coisas em comum, tal como o fato de ambas as disciplinas considerarem a família como foco primário para a compreensão do comportamento humano. Segundo a autora, a colaboração destas duas áreas acabou determinando algumas tendências dentro da pesquisa em psicologia do desenvolvimento, dentre elas o incremento de pesquisas com pais e irmãos, o interesse nas seqüências de interações, nos efeitos bidirecionais e nos conceitos triádicos e ainda a exploração de métodos para descrever o estado do sistema interacional.

Coerente com as idéias da teoria sistêmica, entendemos que o genograma é um instrumento de pesquisa que se destaca por sua praticidade e organização na apresentação 
dos dados, e que se presta perfeitamente ao estudo do desenvolvimento emocional, principalmente quando se pretende investigar o impacto de eventos estressores horizontais e verticais no desenvolvimento infantil, bem como os padrões de relacionamento entre a família atual e de origem. O estudo sugere que vínculos de proximidade afetiva podem garantir maior estabilidade neste importante momento de transição do ciclo vital que é a saída de um fillho da família para entrar na escola.

\section{Referências}

Andolfi, M., \& Angelo, C. (1988). Tempo e mito em terapia famili$\operatorname{ar}$ (R. S. DiLeone, Trad.). Porto Alegre, RS: Artes Médicas.

Balaban, N. (1985). O início da vida escolar. Porto Alegre, RS: Artes Médicas.

Bowlby, J. (1990a). Apego e perda: Vol 1. Apego. São Paulo, SP: Martins Fontes. (Original publicado em 1969).

Bowlby, J. (1990b). Apego e perda: Vol 2. Separação. São Paulo, SP: Martins Fontes. (Original publicado em 1973)

Bowlby, J. (1990c). Apego e perda: Vol 3. Perda. São Paulo, SP: Martins Fontes. (Original publicado em 1980).

Bowen, M. (1991). De la família al individuo. Buenos Aires, Argentina: Paidós. (Original publicado em 1979).

Bromberg, M. H. P. F. (1994). A psicoterapia em situações de perda e luto. São Paulo, SP: Workshopsy.

Brown, F. H. (1995). O impacto da morte e da doença grave sobre o ciclo de vida familiar. In B. Carter \& M. McGoldrick, As mudanças no ciclo de vida familiar (pp. 393-412). Por to Alegre, RS: Artes Médicas.

Carter, B., \& McGoldrick, M. (1995). As mudanças no ciclo de vida familiar. Porto Alegre, RS: Artes Médicas. (Original publicado em 1989).

Castoldi, L. (1997). As configurações familiares e a história de perdas e separações na família: Implicações para a adaptação da criança à pré-escola. Dissertação de Mestrado não-publicada, Curso de Pós-Graduação em Psicologia do Desenvolvimento, Universidade Federal do Rio Grande do Sul, Porto Alegre, RS.

Falicov, J. C. (1991). Transiciones de la familia: Continuidad y cambio en el ciclo de vida. Buenos Aires, Argentina: Amorrurtu.

McGoldrick, M., \& Gerson, R. (1985). Genograms in family assessment. New York: W.W. Norton.

Minuchin, P. (1985). Families and individual development: Provocations from the field of family therapy. Child Development, 56, 289-302.

Minuchin, S., \& Fishman, H. C. (1990). Técnicas de terapia familiar (C. Kinsch \& M. E. F. R. Maia, Trads.). Porto Alegre, RS: Artes Médicas.

Stake, R. E. (1994). Case studies. In N. K. Denzin \& Y. S. Lincoln (Eds.), Handbook on qualitative research (pp. 175-188). London: Sages. 